\title{
Salário mínimo e distribuição de renda no Brasil a partir dos anos $2000^{*}$
}

\author{
João Saboia ** \\ João Hallak Neto ${ }^{* * *}$
}

\begin{abstract}
Resumo
Há vários anos o salário mínimo (SM) vem passando por um intenso processo de crescimento no Brasil. Diversos autores têm argumentado que importante parcela da melhoria da distribuição de renda no passado recente pode ser atribuída ao aumento do SM. A partir do cálculo das elasticidades dos rendimentos em relação ao SM, este artigo procura estimar os efeitos da atual política de reajuste do SM sobre a melhoria da distribuição de renda. O resultado das simulações realizadas mostra que o SM contribuiu bastante nos últimos anos, tanto pelo mercado de trabalho quanto através das pensões, aposentadorias e outras transferências oficiais.
\end{abstract}

Palavras-chave: Salário mínimo; Distribuição de renda; Distribuição da renda familiar; Distribuição funcional da renda; Elasticidade.

\begin{abstract}
The minimum wage and income distribution in Brazil from the 2000s

In recent years the Brazilian minimum wage (MW) has gone through an intense process of growth. Different authors have argued that an important part of the improvement in income distribution can be attributed to the increase in the MW in the recent past. Using income elasticities with respect to MW, this paper seeks to estimate the effects of current MW adjustment policy on improving income distribution. The results of simulations show that MW contributed greatly in recent years through the labor market as well as through pensions and other official transfers.
\end{abstract}

Keywords: Minimum wage; Income distribution; Family income distribution; Functional income distribution; Elasticity.

JEL J30, J38, H53, E24, E27.

\section{Introdução}

Há cerca de duas décadas o salário mínimo (SM) vem passando por um intenso processo de crescimento. Embora sem regras bem definidas para os reajustes até recentemente, a conjuntura política favoreceu a concessão de aumentos reais para o SM. Apenas em 2011 foi aprovada a lei 12.382, fixando as regras para os reajustes anuais do SM, mantendo de certa forma mecanismos que já vinham sendo utilizados

* Artigo recebido em 4 de janeiro de 2016 e aprovado em 4 de novembro de 2016. Os autores agradecem a Jordão Fernandes Andrade pela organização do material empírico e apoio no processamento das simulações da distribuição da renda familiar per capita. Este trabalho faz parte da pesquisa Nopoor financiada pela União Europeia (www.nopoor.eu).

${ }^{* *}$ Professor emérito do Instituto de Economia da Universidade Federal do Rio de Janeiro (IE/UFRJ), Rio de Janeiro, RJ, Brasil. E-mail: saboia@ie.ufrj.br.

*** Analista da Diretoria de Pesquisas do Instituto Brasileiro de Geografia e Estatística (IBGE), Rio de Janeiro, RJ, Brasil. E-mail: joao.hallak@gmail.com. 
na prática. Tal legislação definiu o formato dos reajustes para o período 2012/2015, tendo sido renovado para o novo período 2016/2019 pela a lei 13.152 de 2015 . Em outras palavras, o SM tem recebido a cada ano a correção da inflação pelo INPC, além de aumento real segundo a taxa de crescimento do Produto Interno Bruto (PIB) verificada dois anos antes e assim deverá permanecer até 2019.

O papel do SM sobre a melhoria da distribuição de renda é polêmico. Há autores que defendem que ele é importante, enquanto outros minimizam sua capacidade redistributiva. Usualmente aqueles que minimizam o papel do SM defendem os programas focalizados de distribuição de renda, cujo efeito sobre a redução da pobreza é inquestionável. Em geral, tais críticas se referem ao fato de que as pessoas que recebem o SM no mercado de trabalho, ou através de pensões e aposentadorias, localizam-se nas faixas intermediárias de rendimento, além do fato de que o aumento do salário mínimo repercute desfavoravelmente sobre as contas públicas ${ }^{1}$.

Este artigo defende que o SM tem contribuído para a melhoria da distribuição de renda, utilizando para isso resultados de simulações baseadas na experiência do período recente. Reconhece, entretanto, que há limites no seu potencial redistributivo. Para isso, são desenvolvidas simulações que consideram as diversas formas de inserção dos trabalhadores no mercado de trabalho, além das transferências sociais associadas ao SM.

Os anos analisados vão de 2004 a 2013 quando o SM apresentou grande crescimento em termos reais. São estimadas as elasticidades dos diversos tipos de rendimento do trabalho em relação ao salário mínimo no período. Tais elasticidades são aplicadas à estrutura de rendimentos observada em 2004, simulando-se o que ocorreria com a distribuição de renda supondo-se o crescimento real do SM no período. Em seguida, é comparado o resultado da simulação com a distribuição de renda efetivamente observada em $2013^{2}$.

Tendo em vista o comportamento do mercado de trabalho brasileiro nos últimos anos, quando houve forte crescimento do SM, intensa geração e formalização de empregos e redução das taxas de desemprego, optou-se por não

(1) As diferentes posições em relação ao tema no Brasil estão apresentadas nos vários textos da bibliografia. Entre os artigos mais recentes que discutem o efeito do aumento do SM na redução das desigualdades de rendimentos podem ser mencionados Afonso et al (2011), Brito (2015), Ferreira et al (2014), Komatsu (2013), Neder e Ribeiro (2010), Saboia (2015) e Soares (2010).

(2) Por ocasião da preparação deste texto, os dados da PNAD de 2014 ainda não haviam sido divulgados. Além disso, o crescimento da economia foi praticamente nulo e o SM cresceu muito pouco em 2014. Daí ter se mantido 2013 como ano final do estudo. Quanto ao início do período em 2004, foi uma escolha natural, na medida em que foi quando a economia começou a apresentar taxas de crescimento mais elevadas e quando o aumento do salário mínimo se acelerou. 
utilizar qualquer hipótese relacionando o crescimento do SM com mudanças na estrutura ocupacional do mercado de trabalho nas simulações. $\mathrm{O}$ efeito básico do crescimento do SM considerado é sobre os níveis de rendimento através das elasticidades estimadas para os diversos tipos de trabalhadores. Em outras palavras, considera-se mantida a distribuição ocupacional encontrada em 2004 e simulam-se mudanças nos níveis de rendimentos.

A simulação é completada com a estimativa do efeito do crescimento do SM sobre o piso das pensões e aposentadorias, além do Benefício de Prestação Continuada (BPC), cujo valor é igual ao $1 \mathrm{SM}$.

Além da discussão da distribuição da renda sob o enfoque pessoal/familiar, o artigo analisa também o efeito do aumento do SM sobre a distribuição funcional da renda, que tem favorecido o rendimento do trabalho a partir de 2004. Nessa parte do estudo, é utilizada a elasticidade agregada da renda do trabalho relativamente ao $\mathrm{SM}$, além do crescimento da população ocupada, da massa de remunerações e do rendimento médio no período.

A principal contribuição do artigo é o desenvolvimento de técnicas simples para o cálculo dos efeitos da política do SM sobre a distribuição de rendimentos no período recente em que tal política foi aplicada pelo governo. Além disso, fornece subsídios para a estimativa dos efeitos possíveis no futuro, pelo menos até 2019, na medida em que a legislação do SM foi estendida até aquele ano.

$\mathrm{Na}$ próxima seção são apresentados os resultados das estimativas das elasticidades dos diversos tipos de rendimentos do trabalho em relação ao SM. Em seguida é desenvolvida a metodologia utilizada para o cálculo das simulações do efeito do salário mínimo sobre a distribuição do rendimento pessoal/familiar. A terceira seção ilustra os resultados das simulações em termos de redução da desigualdade de rendimentos. Na quarta seção é desenvolvida a simulação para a distribuição funcional da renda (DFR). Finalmente, são apresentadas as principais conclusões. A fonte básica de dados para o artigo é a PNAD. Para a análise da DFR utilizou-se o Sistema de Contas Nacionais (SCN).

\section{As elasticidades dos rendimentos do trabalho em relação ao salário mínimo}

O Gráfico 1 apresenta a evolução do SM a partir de 1995. Conforme pode ser verificado, houve forte aumento no período, especialmente a partir de meados da década passada, período que será objeto de nosso estudo. O SM cresceu 128,8\% em termos reais entre 1995 e 2014, sendo 35,7\% entre 1995 e 2004 e 68,6\% entre 2004 e 2014. 


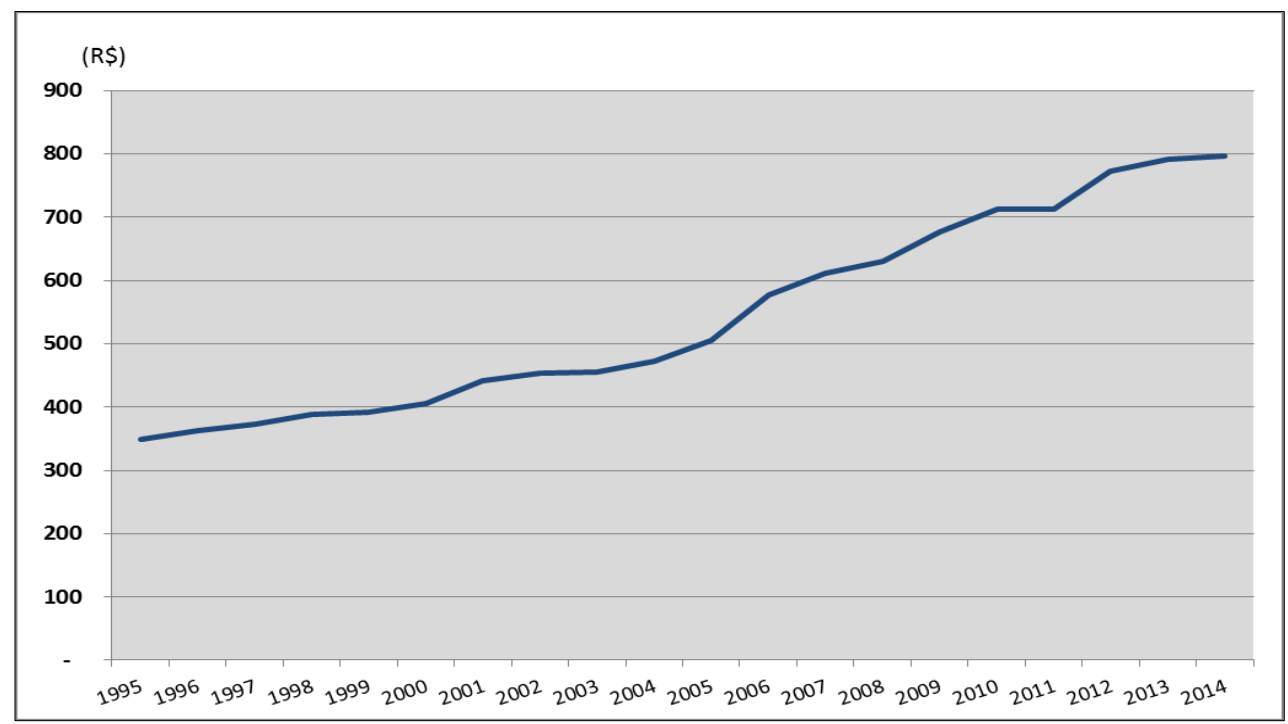

Nota: Valores médios do ano, deflacionados pelo INPC/IBGE.

Valores constantes de julho de 2015.

Fonte: Ipeadata/Ipea.

Saboia (2010) apresentou estimativas para as elasticidades dos rendimentos do trabalho em relação ao SM para o período 1995 e 2006 utilizando dados da PNAD. Três características podem ser destacadas nos resultados encontrados.

Em primeiro lugar, as elasticidades variam muito dependendo da posição na ocupação considerada (empregados, com ou sem carteira assinada, trabalhadores por conta própria, etc.). Em segundo lugar, elas se modificam no interior de cada posição na ocupação, segundo o nível de rendimento do trabalhador. Em terceiro lugar, as elasticidades também mudam ao longo do tempo segundo a conjuntura econômica do período.

Para se obter maior precisão nas simulações, na próxima seção as elasticidades foram estimadas para o período 2004/2013 em seis posições na ocupação com rendimento fornecidas pela PNAD - empregados com e sem carteira assinada, trabalhadores domésticos com e sem carteira assinada, trabalhadores por conta própria e funcionários públicos. Em alguns casos, como nos empregados e trabalhadores domésticos com carteira assinada, a relação com o SM é óbvia. Em outros, como aqueles no setor informal, a relação é indireta, via o "farol" representado pelo SM em termos de remuneração ${ }^{3}$. Para os funcionários públicos ela

(3) Sobre a questão do efeito "farol" do SM sobre os rendimentos do setor informal ver Souza e Baltar (1979). 
é diferenciada, na medida em que suas remunerações são definidas segundo políticas governamentais locais, mas, como o salário mínimo é a remuneração mínima legal, há uma influência direta, pelo menos para os menores salários da administração pública. No caso da renda dos empregadores, optou-se por não utilizar as elasticidades nas simulações na medida em que o SM representa ao mesmo tempo custo e receita. Por um lado, ele representa um gasto maior na folha de pagamentos. Por outro lado, pode também representar mais receita pelo aumento da demanda. Assim, optou-se por um efeito neutro, mantendo-se constante o rendimento real dos empregadores nas simulações realizadas.

Os dados brutos das elasticidades foram ajustados pelo procedimento de médias móveis de três pontos para suavizar os desníveis entre valores adjacentes. Os Gráficos 2 a 7 ilustram os resultados encontrados para os vigésimos da distribuição de rendimentos para as seis posições na ocupação utilizadas nas simulações ${ }^{4}$.

Conforme pode ser verificado, as elasticidades para os empregados com carteira assinada são próximas à unidade apenas nos três primeiros vigésimos onde se encontram os salários iguais ao mínimo. A partir daí tendem a decrescer, caindo bastante nos maiores níveis salariais. $\mathrm{O}$ valor médio da elasticidade foi de apenas 0,38, sendo o menor entre os seis grupos analisados. Em termos de rendimento, entretanto, representam o segundo nível mais elevado. Portanto, o SM atuaria com um forte efeito desconcentrador de renda entre os empregados do setor formal da economia.

Os resultados para os empregados sem carteira assinada são surpreendentes, apresentando elasticidades próximas à unidade, com pequena queda nos níveis mais elevados. A elasticidade média atinge 0,95 . Isso confirma o efeito "farol" do salário mínimo para esses trabalhadores informais, podendo ser explicado também pelos baixos níveis salariais dos empregados sem carteira assinada. Esse é o terceiro grupo em termos de menores rendimentos médios, superando apenas os trabalhadores domésticos com ou sem carteira assinada. Portanto, as elevadas elasticidades encontradas entre os empregados sem carteira assinada certamente contribuíram para a redução das desigualdades de rendimentos como um todo.

(4) O método utilizado para a estimação das elasticidades médias no período 2004/2013 é bastante simples. Calculou-se para cada vigésimo da distribuição de rendimentos do trabalho principal o quociente entre a variação dos respectivos rendimentos médios e a variação do SM no período. No ajustamento por médias móveis foram mantidos os valores extremos ( $1^{\circ}$ e $20^{\circ}$ vigésimos). Foram utilizados os valores reais dos rendimentos e do $\mathrm{SM}$ deflacionados pelo INPC para o cálculo das elasticidades. 
Gráfico 2

Elasticidades dos vigésimos dos rendimentos médios dos empregados com carteira assinada em relação ao $\mathrm{SM}-2004 / 2013$

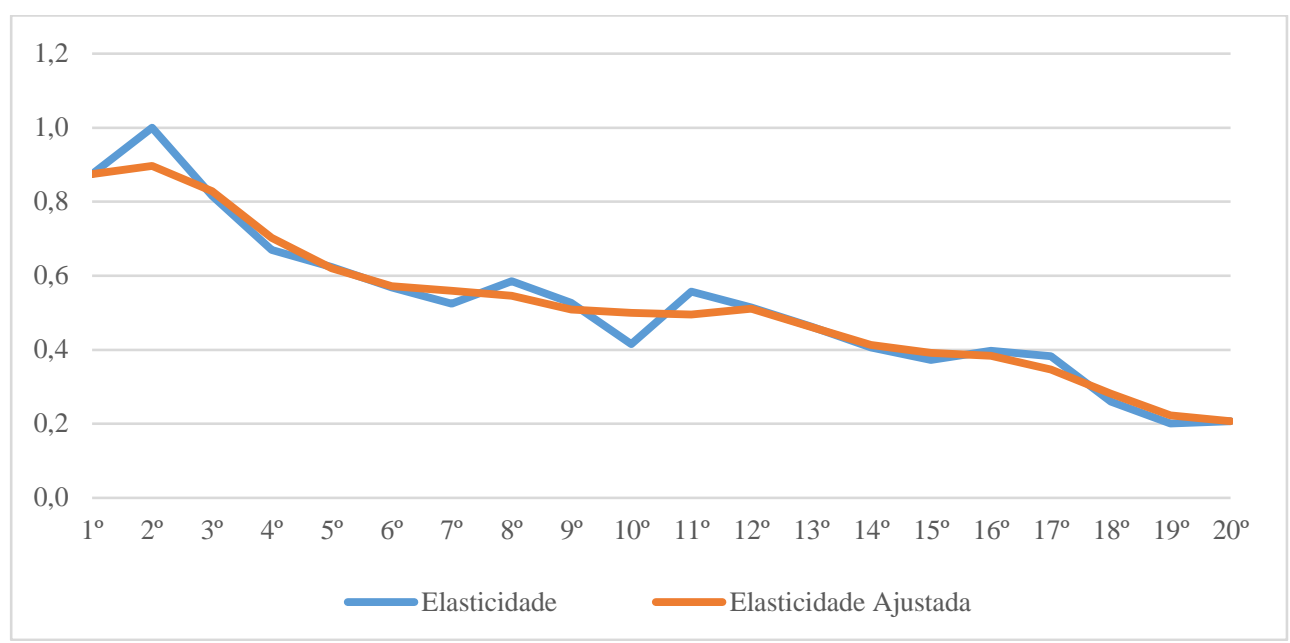

Fonte: Processamento dos autores a partir da Pnad e do Ipeadata/Ipea.

\section{Gráfico 3}

Elasticidades dos vigésimos dos rendimentos médios dos empregados sem carteira assinada em relação ao SM - 2004/2013

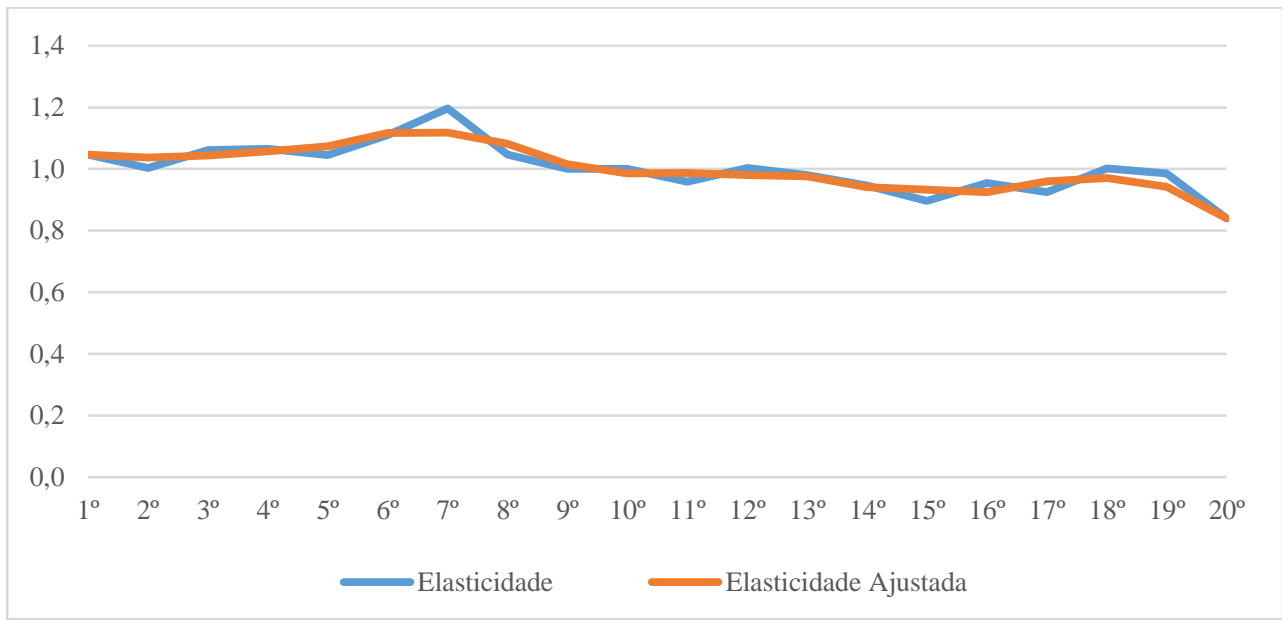

Fonte: Processamento dos autores a partir da Pnad e do Ipeadata/Ipea.

No caso dos trabalhadores domésticos com carteira, a regra geral é a obtenção de elasticidades unitárias na primeira metade da distribuição, correspondente aos trabalhadores que recebem um salário mínimo ou valores muito 
próximos. Na segunda metade as elasticidades caem um pouco, baixando para cerca de 0,6 nos níveis salariais mais elevados. A elasticidade média atingiu 0,81.

Para os empregados domésticos sem carteira assinada ocorre o inverso. As elasticidades começam com valores pouco superiores a 0,8 nos menores salários (bem abaixo do SM) e atingem elasticidades unitárias nos maiores níveis remunerações, próximas ou mesmo superiores ao salário mínimo. Desta forma, o SM poderia ter um efeito concentrador de renda entre tais empregados, na medida em que os menores níveis salariais são menos afetados pela política do SM. Os empregados domésticos são os trabalhadores com os menores rendimentos entre os seis grupos analisados. Sua elasticidade média é elevada atingindo $0,95^{5}$.

\section{Gráfico 4}

Elasticidades dos vigésimos dos rendimentos médios dos domésticos com carteira assinada em relação ao SM - 2004/2013

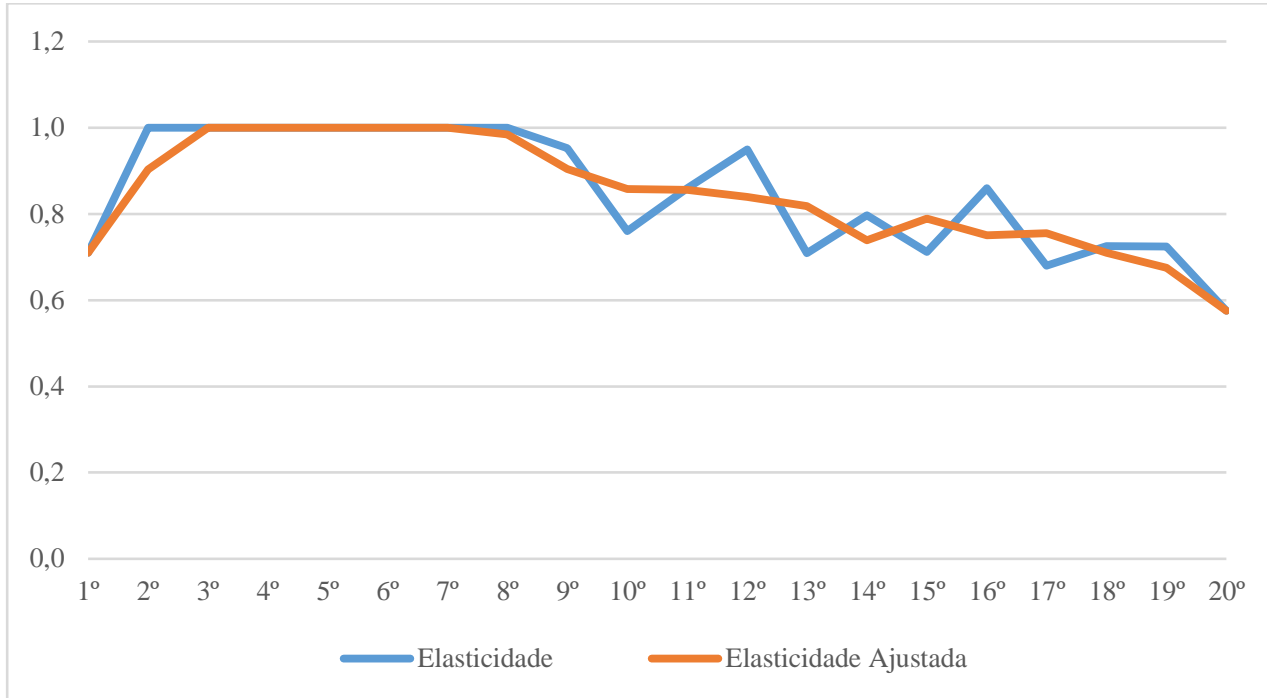

Fonte: Processamento dos autores a partir da Pnad e do Ipeadata/IPEA.

(5) Oliveira e Hoffmann (2015) encontrou um comportamento semelhante para os empregados sem carteira assinada na agricultura mostrando que os menores rendimentos de tais trabalhadores são pouco influenciados pelo SM, relativizando assim o chamado efeito "farol" para níveis muito baixos de rendimento. 


\section{Gráfico 5}

Elasticidades dos vigésimos dos rendimentos médios dos domésticos sem carteira assinada em relação ao SM - 2004/2013

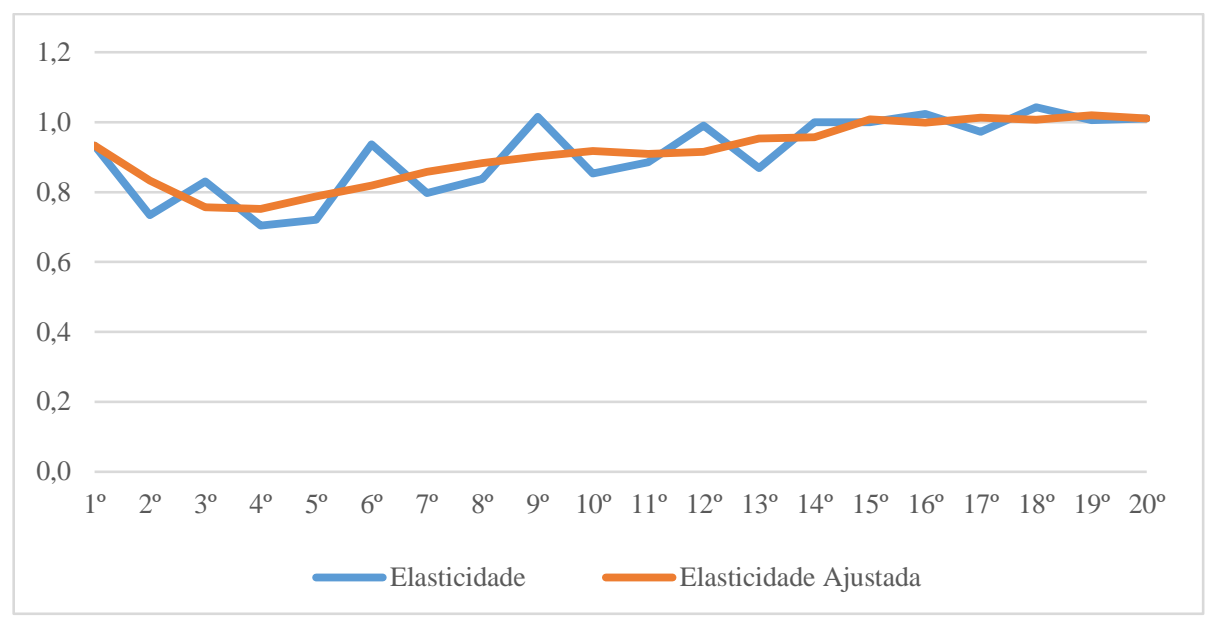

Fonte: Processamento dos autores a partir da Pnad e do Ipeadata/Ipea.

Os trabalhadores por conta própria possuem mecanismos diferenciados de formação da renda do trabalho. Sua relação com o SM é mais complexa. Eles apresentam uma curva descendente para as elasticidades, baixando de cerca de 1,2 nos menores níveis de rendimentos a 0,5 para os rendimentos mais elevados, possuindo também um formato tipicamente redistributivo. Tais trabalhadores apresentam o segundo nível mais elevado de rendimento médio. A elasticidade média foi estimada em 0,72 .

Gráfico 6

Elasticidades dos vigésimos dos rendimentos médios dos trabalhadores por conta própria em relação ao $\mathrm{SM}$ - 2004/2013

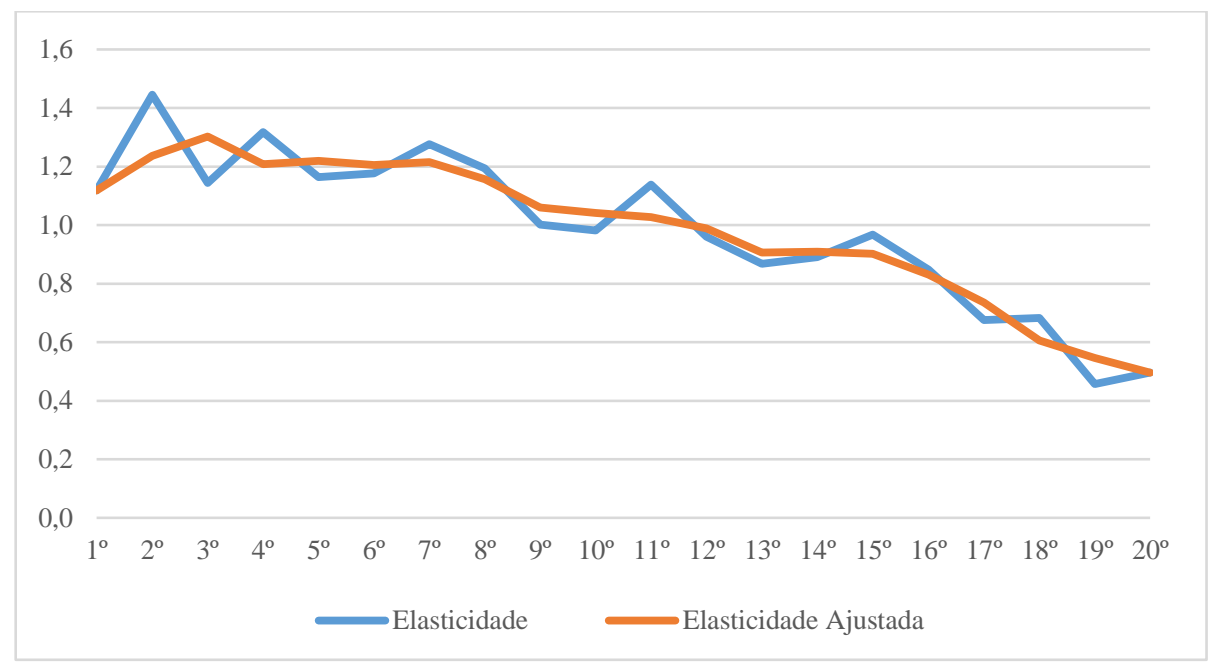

Fonte: Processamento dos autores a partir da Pnad e do Ipeadata/Ipea. 
No caso dos funcionários públicos e militares as elasticidades são sistematicamente inferiores às unidades, em torno de 0,8 , exceto nos menores níveis salariais, que correspondem à remuneração equivalente ao SM, onde atingem o valor unitário. A elasticidade média é 0,76 , representando o grupo de maiores rendimentos médios.

\section{Gráfico 7}

Elasticidades dos vigésimos dos rendimentos médios de militares ou funcionários públicos em relação ao SM - 2004/2013

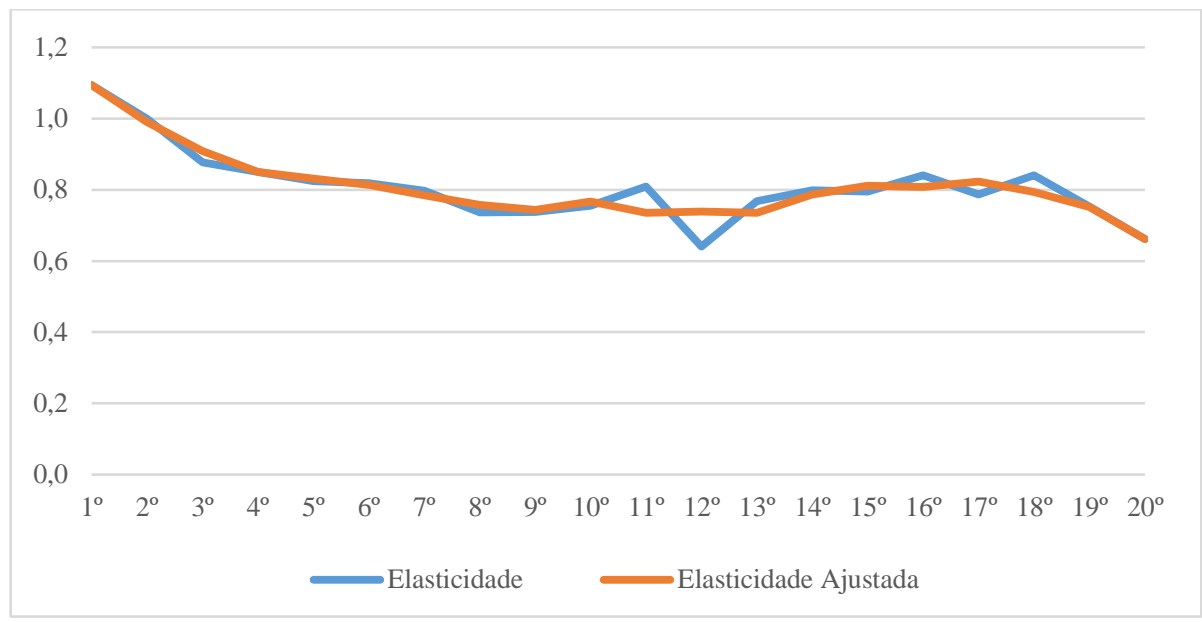

Fonte: Processamento dos autores a partir da Pnad e do Ipeadata/IPEA.

Em resumo, os resultados obtidos acima confirmam a grande variedade do comportamento das elasticidades e a tendência para a obtenção de valores mais elevados para os menores rendimentos e na faixa onde os trabalhadores recebem exatamente um salário mínimo. Tais resultados indicam um potencial favorável para o crescimento do SM em termos de melhoria da distribuição de renda.

As elasticidades ajustadas dos vigésimos da distribuição de renda das seis posições na ocupação apresentadas acima serão utilizadas nas simulações desenvolvidas mais adiante.

\section{A metodologia utilizada para as simulações da distribuição da renda familiar per capita $^{6}$}

As simulações do efeito do aumento do SM sobre a distribuição de rendimentos são feitas em várias etapas. A renda utilizada foi a renda familiar per

(6) Metodologia semelhante foi utilizada em Saboia (2015). 
capita, que reflete razoavelmente o nível de bem-estar das famílias. O ponto de partida é a distribuição de renda familiar per capita de 2004.

São utilizadas diversas taxas de crescimento real para o SM. No caso do rendimento do trabalho, utilizaram-se os valores das elasticidades ajustadas dos vigésimos para cada tipo de posição na ocupação, de modo a verificar qual seria a mudança na distribuição do rendimento familiar per capita para um determinado aumento real do SM.

No caso dos rendimentos de pensões e aposentadorias oficiais, cujo piso é o próprio salário mínimo, a simulação é bastante simples, bastando deslocar todas as pessoas que recebem entre o velho e o novo SM para o valor do novo SM. Exemplificando, se o aumento real do SM for de $10 \%$, todos os aposentados e pensionistas que recebiam entre o piso e $10 \%$ acima do piso são reajustados para o novo valor do SM. Os demais permanecem com os valores inalterados?

Um terceiro grupo de pessoas também tem seus rendimentos reajustados quando o SM aumenta. Trata-se daqueles que recebem o Benefício de Prestação Continuada (BPC), cujo valor é igual a 1 SM. A localização desse tipo de rendimento na PNAD não é simples, pois fica incluído nos "outros rendimentos". A hipótese utilizada neste caso é que todas as pessoas que recebem exatamente $1 \mathrm{SM}$ nessa rubrica estariam recebendo o BPC. Portanto, esses rendimentos são reajustados na mesma proporção que o SM nas simulações efetuadas ${ }^{8}$.

Cabe observar que as simulações apresentadas a seguir não consideram qualquer efeito do reajuste do SM sobre outros tipos de rendimentos que não sejam do trabalho, como alugueis, doações, ganhos financeiros, etc. Conforme é sabido, a capacidade da PNAD em captar rendimentos que não sejam do trabalho, de pensões e de aposentadorias é muito limitada. Também não se considera qualquer efeito sobre a entrada e saída de trabalhadores no mercado de trabalho, mantendo-se, portanto, a distribuição original dos trabalhadores ${ }^{9}$.

Ao se tentar isolar o efeito do SM sobre os diversos rendimentos do trabalho sem considerar outras variáveis que também influenciam a evolução dos

(7) $\mathrm{Na}$ prática, é isso que tem ocorrido na medida em que o governo tem corrigido as pensões e aposentadorias oficiais segundo o INPC, sem qualquer aumento real nos últimos anos. Como estamos trabalhando com variações reais, crescimento real nulo significa manter "os valores inalterados".

(8) Os dados do BPC na PNAD são pouco confiáveis por estarem junto com diversos outros rendimentos, inclusive ganhos com juros. Daí a menor confiabilidade nos resultados das simulações obtidas para o BPC. Como o BPC destina-se a pessoas idosas e/ou deficientes (jovens ou idosas), fica difícil a utilização de filtros etários para a identificação daqueles que estão efetivamente recebendo BPC. O total de pessoas recebendo o BPC identificadas no item "outros rendimentos" da PNAD é menor do que o número de benefícios efetivamente pagos pelo governo sob essa rubrica.

(9) A hipótese implícita aqui é que eventuais entradas e saídas podem ocorrer mas mantêm a distribuição original. 
rendimentos é possível que as elasticidades estimadas possam apresentar algum viés, inclusive pelo fato de estarmos tratando de variáveis crescentes e não estacionárias. Como o objetivo do artigo é verificar o papel do SM sobre os vigésimos da distribuição da renda do trabalho, a hipótese implícita é que o eventual viés seria relativamente uniforme nas diversas faixas de renda, não prejudicando as principais conclusões encontradas sobre o papel redistributivo da política do SM do país.

Dessa forma, os resultados da próxima seção devem ser entendidos como um exercício de simulação, representando uma aproximação do papel do aumento do SM na melhoria da distribuição de rendimentos.

\section{Resultados das simulações para a distribuição da renda familiar per capita}

O resultado das simulações pode ser analisado através dos dados da Tabela 1 que mostram o valor do índice de Gini da distribuição do rendimento familiar per capita em 2004 e sua evolução na medida em que o salário mínimo apresenta crescimentos reais de $10 \%$ até $70 \%$. Apresenta também uma coluna para a taxa de crescimento de $67,4 \%$ que foi o crescimento real do salário mínimo no período 2004/2013.

Tabela 1

Índices de Gini da distribuição do rendimento familiar per capita segundo os percentuais de aumentos de SM

\begin{tabular}{|c|c|c|c|c|c|c|c|c|c|}
\hline Modificações & 2004 & $10 \%$ & $20 \%$ & $30 \%$ & $40 \%$ & $50 \%$ & $60 \%$ & $67.4 \%$ & $70 \%$ \\
\hline Aposentadorias & 0.578 & 0.577 & 0.575 & 0.574 & 0.573 & 0.572 & 0.571 & 0.571 & 0.570 \\
\hline Pensões & 0.578 & 0.577 & 0.577 & 0.577 & 0.576 & 0.576 & 0.576 & 0.575 & 0.575 \\
\hline $\begin{array}{l}\text { Somente Outros } \\
\text { Rendimentos (BPC) }\end{array}$ & 0.578 & 0.578 & 0.578 & 0.577 & 0.577 & 0.577 & 0.577 & 0.577 & 0.577 \\
\hline $\begin{array}{l}\text { Transferências } \\
\text { (Aposentadoria, Pensão e }\end{array}$ & 0.578 & 0.576 & 0.574 & 0.572 & 0.571 & 0.569 & 0.568 & 0.567 & 0.567 \\
\hline $\begin{array}{l}\text { Somente Rendimento do } \\
\text { Trabalho Principal }\end{array}$ & 0.578 & 0.573 & 0.569 & 0.567 & 0.566 & 0.566 & 0.566 & 0.567 & 0.567 \\
\hline $\begin{array}{l}\text { Todos os rendimentos } \\
\text { anteriores }\end{array}$ & 0.578 & 0.570 & 0.564 & 0.560 & 0.556 & 0.554 & 0.552 & 0.551 & 0.551 \\
\hline
\end{tabular}

Fonte: Processamento dos autores.

Conforme pode ser verificado, na medida em que o salário mínimo cresce, o índice de Gini tende a cair. Note-se, entretanto, que a intensidade da queda se reduz quando se consideram taxas mais elevadas de crescimento do SM. Enquanto em 2004 o valor era 0,578 , as simulações mostram que com o aumento de 67,4\% para o salário mínimo, o índice baixaria para 0,551 . Na realidade, o índice de Gini encontrado em 2013 foi 0,530. Portanto, o aumento do salário mínimo teria sido 
responsável por $56 \%$ da queda da desigualdade de rendimentos medida pelo índice de Gini.

Cabe notar que, isoladamente, o BPC e as pensões contribuem pouco para a queda da desigualdade, na medida em que suas respectivas massas de rendimentos são relativamente pequenas no total de rendimentos levantado pela PNAD $^{10}$. Já as aposentadorias e os rendimentos do trabalho possuem um potencial bem mais elevado de contribuição para a redução das desigualdades. Em seu conjunto, as transferências (aposentadorias, pensões e BPC) seriam responsáveis pela redução do índice de Gini para 0,567, mesmo valor encontrado para a redução obtida com os rendimentos do trabalho. Em outras palavras, transferências e rendimentos do trabalho seriam responsáveis, cada um, por cerca da metade da redução observada no índice de Gini no período.

O Gráfico 8 resume os resultados encontrados, mostrando as respectivas quedas no índice de Gini segundo diferentes taxas de crescimento do salário mínimo real. Cabe notar que o efeito desconcentrador do rendimento do trabalho é muito forte para taxas de crescimento real do SM mais baixas, perdendo força para taxas acima de 50\%. Em contrapartida, o efeito das transferências é menor para taxas de crescimento do SM relativamente pequenas, mas continua atuando a ponto de se igualar ao obtido pelo rendimento do trabalho no final do período analisado.

\section{Gráfico 8}

Evolução do índice de Gini da distribuição do rendimento familiar per capita a partir de 2004 segundo a taxa de crescimento real do SM

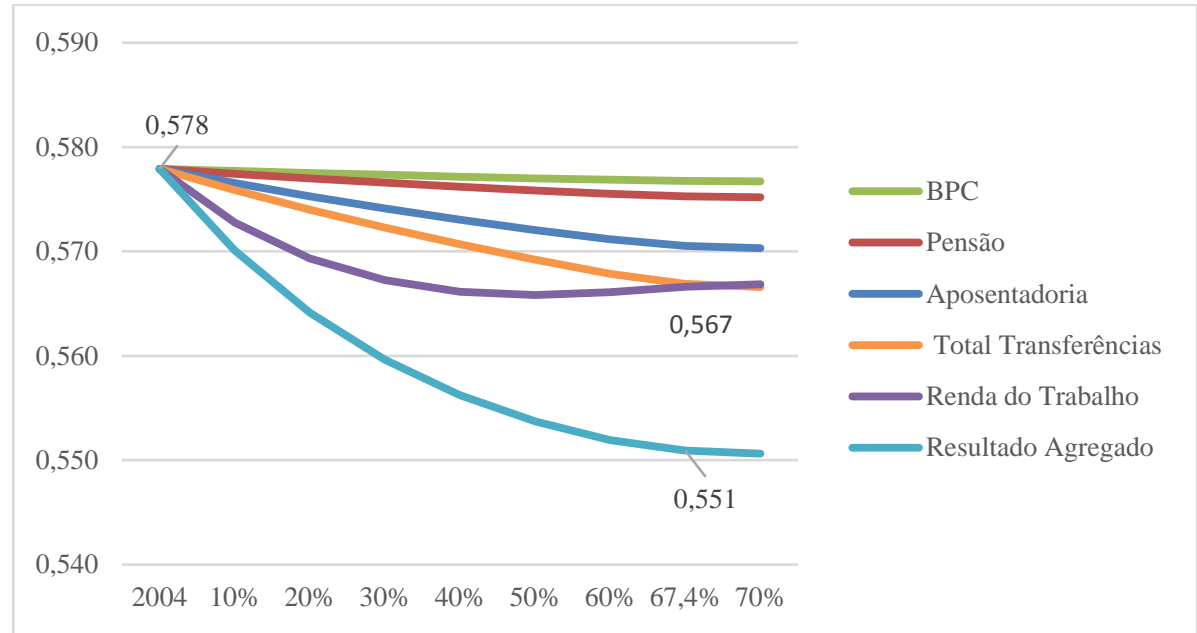

Fonte: Processamento dos autores.

(10) Os rendimentos do trabalho representam cerca de três quartos dos rendimentos levantados pela PNAD. Pensões e Aposentadorias, menos de $20 \%$, sendo a maior parte referente a aposentadorias. A participação do BPC é marginal. 
Segundo as simulações aqui desenvolvidas, a melhoria da distribuição de renda observada através da queda do índice de Gini é obtida com a redução relativa da participação do décimo superior e transferência de parte de seus rendimentos para os décimos inferiores, com maiores benefícios para as pessoas do quarto ao oitavo décimo da distribuição. Cabe notar que o efeito redistributivo do aumento do SM sobre os três primeiros décimos da distribuição de renda é mínimo, na medida em que as pessoas pertencentes a essas famílias recebem rendimentos muitos baixos, em geral inferiores ao SM.

Os resultados encontrados através das simulações apresentam a mesma tendência, mas mostram algumas diferenças com os obtidos por Brito (2015). A autora, utilizando outra metodologia no período 1995/2013, estimou que o salário mínimo teria sido responsável por $72,4 \%$ da redução do índice de Gini do rendimento domiciliar per capita, sendo mais intenso o papel representado pelas pensões e aposentadorias $(37,7 \%)$, seguindo-se o mercado de trabalho $(26,3 \%)$ e o BPC $(8,4 \%)$. Em outras palavras, as transferências teriam tido um papel mais importante que os salários na redução das desigualdades. Cabe, entretanto, ressaltar as diferenças nas metodologias e nos períodos analisados pelos dois estudos ${ }^{11}$.

\section{Salário mínimo e distribuição funcional da renda}

Uma forma complementar de analisar o fenômeno distributivo é por meio de sua distribuição funcional, que se refere à repartição da renda gerada pelos fatores utilizados na produção. O termo funcional indica que a repartição da renda é realizada considerando-se a "função" desempenhada pelos agentes no processo de produção. A partir desta distribuição primária, definem-se as participações dos rendimentos do trabalho e do capital na renda gerada. Tais relações têm sua origem no Sistema de Contas Nacionais (SCN) e são obtidas por meio da desagregação do PIB pela ótica da renda.

Os componentes da ótica da renda do PIB são registrados na segunda conta do SCN, a conta de geração da renda. O saldo que abre esta conta é o valor adicionado, que equivale à diferença entre o valor da produção e o dos consumos intermediários necessários para se realizar tal produção, constituindo-se assim no valor efetivamente criado pelas unidades durante a atividade produtiva em um determinado período.

Assim, o valor adicionado é repartido entre a remuneração dos empregados, que compete ao trabalho despendido pelos assalariados, os impostos sobre a produção líquidos de subsídios (ILPI) que o Governo deduz da produção, o excedente operacional bruto (EOB) que remunera os ativos utilizados pelas unidades

(11) O fato de se utilizar o rendimento domiciliar per capita ou o familiar per capita faz pouca diferença em termos de resultados distributivos. 
empresariais, e o rendimento misto bruto (RMB) destinado às famílias $\operatorname{produtoras}^{12}$.

O foco desta seção é estimar o efeito de elevações do SM sobre a participação da remuneração do trabalho assalariado, a massa de remunerações (MR), no PIB. A elevação real do SM no período 2004/2013 influenciou positivamente a variação da MR, que cresceu em proporção superior ao aumento do PIB, ocasionando a elevação de seu peso na DFR.

Em termos quantitativos, dois efeitos podem explicar a elevação da MR: i) o aumento dos postos de trabalho assalariados na economia e/ou ii) o aumento dos rendimentos médios do trabalho assalariado (RM). O crescimento do SM impacta o RM e a massa de remunerações, e consequentemente seu peso na DFR. Além disso, procura-se mensurar em que grau o aumento do SM influenciou a remuneração média recebida pelos trabalhadores na economia brasileira e, esta última, no crescimento da massa de remuneração (MR) no PIB.

Os resultados da ótica da renda estão disponíveis na série histórica publicada pelo IBGE sob a nova referência do SCN para a economia brasileira de 2000 a 2013. Esta nova série, fundamentada na mais recente revisão do manual internacional de contas nacionais, o SNA-2008, possui referência no ano 2010 e foi divulgada pelo IBGE em $2015^{13}$.

O Gráfico 9 apresenta a evolução da participação dos componentes do PIB pela ótica da renda no período disponível durante o período de referência da série atual do SCN. Nota-se que no início da década de 2000, as remunerações perdem participação para o EOB; invertendo-se esta tendência a partir de 2004, que vem a ser o ponto de partida para a análise desenvolvida. Em relação aos outros componentes, ILPI e RMB, o primeiro aumenta sua participação a partir de 2000 e prossegue em relativa estabilidade, já o RMB sofre uma queda contínua de participação desde o início da série e uma estabilização em patamar inferior nos anos finais ${ }^{14}$.

(12) A definição pormenorizada dos componentes da ótica da renda no PIB pode ser encontrada no manual internacional do SCN, o SNA-2008 (UN, 2009, cap. 7), e na nota metodológica do SCN do Brasil (IBGE, 2014).

(13) Os novos resultados do SCN, divulgados em novembro de 2015 , podem ser acessados no link da publicação (IBGE, 2015): http://www.ibge.gov.br/home/estatistica/economia/contasnacionais/2013/default.shtm.

(14) Hallak Neto e Saboia (2014) interpretam os movimentos dos componentes DFR no período 19952009, utilizando a série de referência anterior do SCN. A análise é coincidente para o período 2000-2009 aqui apresentado, pois praticamente não houve alteração entre uma série e outra no que concerne às variações dos componentes. Por este motivo os autores restringirão seus comentários acerca dos movimentos das variáveis ao período após 2009. 
Gráfico 9

Participação dos componentes do PIB pela ótica da renda no Brasil - 2000/2013

(\%)

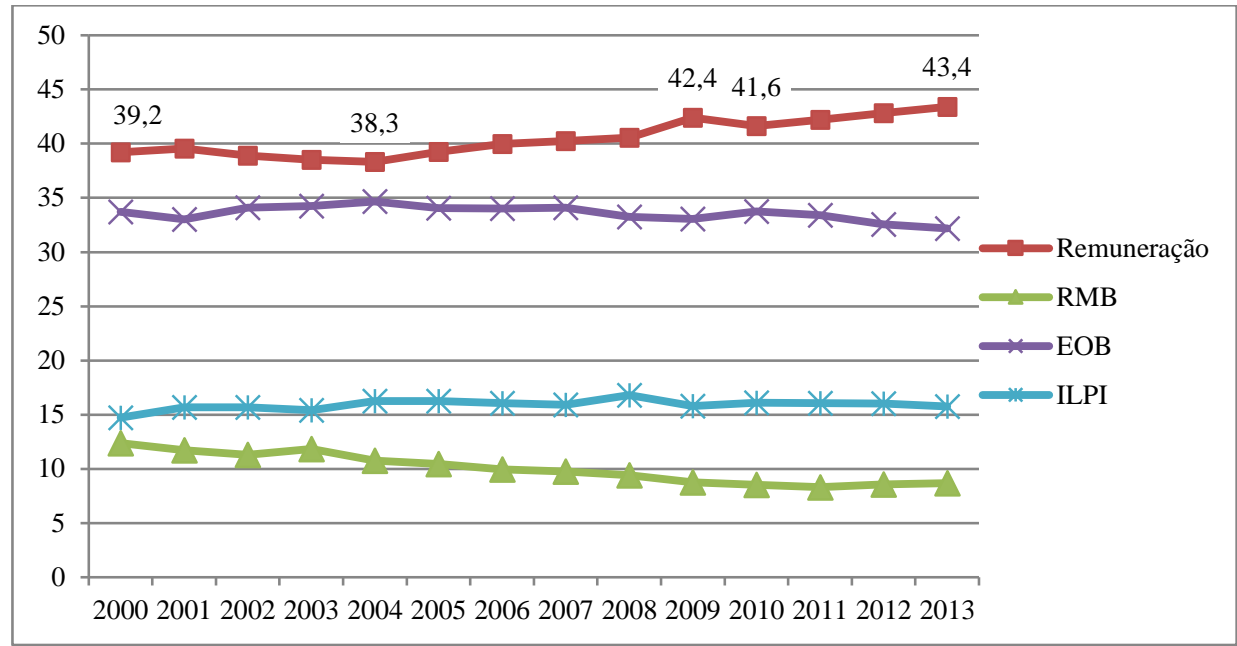

Fonte: SCN/IBGE.

O ponto de mínimo da parcela de remunerações sobre o PIB na série histórica ocorreu em 2004, quando esta registrou 38,3\%. Sua recuperação prosseguiu continuamente até 2010, resistindo até mesmo à forte desaceleração do PIB em 2009. A partir de 2004 houve ampliação do nível de ocupação da população economicamente ativa, aumento da formalização no trabalho e substanciais melhorias na remuneração, que perdurou até o último ano da série. Em 2013, portanto, este componente atingiu o ponto máximo de representação no PIB (43,4\%), ou seja, um ganho de 5,1 pontos percentuais (pp) no período.

Deve-se observar que o valor do SM, variável fundamental para a determinação de grande parte das remunerações no país, recebeu contínuos reajustes acima da inflação no período $2004 / 13^{15}$. Outro sinal que reforça este movimento de recuperação das remunerações foi a obtenção sistemática pelos trabalhadores organizados de aumentos salariais acima da inflação a partir da segunda metade da década de $2000^{16}$.

Enquanto a participação das remunerações sofreu pequeno recuo em 2010 para retornar à trajetória ascendente nos três últimos anos da série, com o EOB ocorreu o inverso. Em 2010, ano em que a taxa de crescimento do PIB alcançou $7,5 \%$, a mais alta desde 1985, entende-se que todos os agentes econômicos ganharam

(15) De 2005 a 2013, os aumentos médios reais do salário mínimo, deflacionados pelo INPC, alcançaram expressivos 5,9\% a.a., ao passo que de 2000 a 2004, estes atingiram 3,9\% a.a.

(16) Detalhes em Hallak Neto (2013, p. 67). 
em termos absolutos. Entretanto, esta "folga de PIB" foi canalizada majoritariamente para o capital, que recuperou parte de sua participação perdida nos anos anteriores.

Nos anos seguintes, com a redução do ritmo de crescimento do PIB, a massa de remunerações voltou a ganhar peso na DFR. Fontes tradicionais do mercado de trabalho como RAIS, PME e Pnad registraram resultados bastante favoráveis aos trabalhadores até 2013, no que tange à ocupação e ao incremento da renda do trabalho ${ }^{17}$.

Portanto, a desaceleração do crescimento do PIB no período 2011-2013 (média de 2,9\% ao ano no triênio) aliada à manutenção do aquecimento do mercado de trabalho e dos ganhos salariais, justificaram o comportamento das remunerações e do EOB na DFR nos anos finais da série.

\subsection{Estimação do impacto da variação do salário mínimo}

De 2004 a 2013, o SM cresceu 67,4\% em termos reais $(167,6 \%$ em termos nominais) trazendo impactos ao crescimento da massa de remuneração (MR), que por sua vez ganhou expressivos 5,1 pp de peso na DFR no período, como apresentado no Gráfico 10. No mesmo período, segundo a Pnad, o incremento da população ocupada assalariada (PO) na economia passou de 59,2 milhões para 72,2 milhões, sendo este, portanto, o outro fator que ocasionou o aumento da MR. Assim, quantitativamente, pode-se atribuir o crescimento da MR a estes dois efeitos: i) o aumento de $21,9 \%$ na PO e ii) a elevação do rendimento médio real dos ocupados em $57,8 \%{ }^{18}$. Considerando estas variações, atribui-se, proporcionalmente, o peso de $27,5 \%$ ao primeiro efeito (PO) e de $72,5 \%$ ao segundo efeito (RM real). Estas informações encontram-se organizadas na Tabela 2.

Para o período em análise, a elasticidade SM-RM foi estimada em 0,857. O cálculo foi obtido por meio da variação percentual do RM dividido pela variação percentual do SM, em termos reais, entre 2004 e 2013. Esta alta correlação era esperada, pois a estrutura de empregos assalariados da economia brasileira é bastante concentrada em ocupações que recebem até dois $\mathrm{SM}^{19}$. Assim, a influência do SM sobre a massa de remunerações foi equivalente a $62,2 \%(72,5 \%$ x 0,857$)$. Considerando que a elevação do peso das remunerações no PIB foi de 5,1 pp, podese dizer que 3,2 pp desta elevação são atribuídos às elevações do SM no período, por

(17) Saboia e Kubrusly (2014) apresentam um indicador multidimensional que confirma a melhora do mercado de trabalho até 2013. Para se ter uma ideia, a menor taxa de desocupação da série histórica da PME ocorreu justamente em 2013, com média de 5,4\%.

(18) O uso do RM real se justifica para isolar o efeito preço desta variável monetária na decomposição da massa de remunerações. Como PO é uma variável em termos reais, o efeito preço ficaria completamente associado ao componente de RM, majorando sua contribuição no comportamento da MR.

(19) Segundo a Pnad, aproximadamente $2 / 3$ da população ocupada assalariada situa-se na faixa de até 2 SM de rendimento mensal. 
intermédio de sua influência no rendimento médio da população ocupada assalariada.

Tabela 2

Variáveis e resultados para o cálculo do impacto da variação do SM na DFR no período 2004-2013

\begin{tabular}{|c|c|c|c|c|}
\hline Variável & $\begin{array}{c}\text { fonte/ } \\
\text { unidade }\end{array}$ & 2004 & 2013 & 2013/04 \\
\hline População ocupada assalariada (POA) & (Pnad, milhares) & 59.259 & 72.248 & $21,9 \%$ \\
\hline Salário mínimo nominal & (R\$ mês) & 253 & 678 & $167,6 \%$ \\
\hline Remuneração nominal & (SCN, R\$ milhões) & 750.180 & 2.307 .327 & $207,6 \%$ \\
\hline Remuneração média nominal & $(R \$)$ & 12.659 & 31.936 & $152,3 \%$ \\
\hline Salário mínimo real (SM)* & (R\$ mês) & 253 & 424 & $67,4 \%$ \\
\hline Remuneração real* & (SCN, R\$ milhões) & 750.180 & 1.442 .981 & $92,4 \%$ \\
\hline Remuneração média real (RM)* & $(R \$)$ & 12.659 & 19.973 & $57,8 \%$ \\
\hline Elasticidade SM-RM & & & & 0,857 \\
\hline peso da var. da POA na Remuneração & (\%) & & & $27,5 \%$ \\
\hline peso da var. da RM na Remuneração & $(\%)$ & & & $72,5 \%$ \\
\hline Influência SM-Remuneração & $(\%)$ & & & $62,2 \%$ \\
\hline Remuneração/PIB & (pp) & 38,3 & 43,4 & 5,1 \\
\hline Efeito do SM em Remuneração/PIB & (pp) & & & 3,2 \\
\hline \multicolumn{2}{|l|}{ * Deflacionados pelo INPC, a preços de 2004.} & & & \\
\hline
\end{tabular}

Fonte: Elaboração dos autores a partir de Pnad e SCN/IBGE.

Este exercício simplificado de desagregação dos componentes que determinam a massa de remuneração assalariada contida na ótica da renda e de quantificação do efeito da variação do SM confirma que a política de reajuste do SM desempenha papel decisivo nos resultados da DFR. Entretanto, cabe observar a importância de outras condições para a definição da DFR, uma vez que esta envolve, além do montante de salários e contribuições, o rendimento das empresas, dos proprietários de imóveis e dos detentores de títulos financeiros, bem como o montante destinado aos impostos sobre a produção. Fatores como a estrutura produtiva, o grau de formalização do mercado de trabalho, as taxas de inflação e os efeitos das decisões de políticas econômicas (monetária, tributária, físcal e cambial) também exercerão influência, mais ou menos direta, sobre como a renda gerada será distribuída entre os agentes econômicos.

Em relação às previsões, ao contrário do que tende a ocorrer na distribuição de renda familiar, não se pode estabelecer, a priori, uma relação direta entre estagnação (ou desaceleração, ou recessão) e queda da participação das remunerações na DFR. Se o PIB e o EOB forem mais afetados que a remuneração, esta poderá ganhar peso, como observado no ano de 2009. Ainda que a política de reajuste do SM represente ganhos menores no futuro, se estes forem maiores do que a variação do PIB, será possível observar ainda a continuidade de ganho de peso da remuneração na DFR. 


\section{Conclusão}

O SM passou nas duas últimas décadas por intensa recuperação. Beneficiado inicialmente por uma conjuntura política relativamente favorável e posteriormente pela própria recuperação da economia, o SM cresceu 128,8\%, em termos reais, entre 1995 e 2014.

Desde 2011 existe uma legislação específica para o SM com reajustes anuais calculados pela inflação do ano anterior acrescida do crescimento do PIB de dois anos anteriores. Em 2015 tais regras foram estendidas até 2019.

Há um reconhecimento unânime entre os especialistas de que o SM teve um papel importante na melhoria da distribuição de renda nos últimos anos, tanto pela via do mercado de trabalho quanto através dos diversos mecanismos de transferências. Isso, entretanto, não tem poupado o SM de críticas por parte daqueles que apontam para as dificuldades atuais das contas públicas e o papel do salário mínimo no aumento das despesas orçamentárias devido à utilização de seu valor como piso para as pensões e aposentadorias oficiais, além de definir o próprio valor do BPC.

Foram desenvolvidas neste artigo duas metodologias para estimar o papel do salário mínimo na melhoria da distribuição de renda no período recente, iniciado em 2004. As duas utilizam a noção de elasticidade dos rendimentos do trabalho em relação ao salário mínimo. A primeira é voltada para o rendimento familiar per capita enquanto a segunda trata da distribuição funcional da renda.

No primeiro caso foi estimado que o salário mínimo explicaria mais da metade da queda do índice de Gini da distribuição do rendimento familiar per capita entre 2004 e 2013. Por outro lado, mostrou também que o mercado de trabalho e as transferências foram igualmente responsáveis pela melhoria da distribuição de renda. Os resultados obtidos com as simulações indicam que, embora o índice de Gini continue caindo na medida em que o SM cresce, a queda vai diminuindo para taxas mais elevadas de crescimento do SM, apontando, portanto, para a perda de eficiência do SM em termos de redução das desigualdades de renda das pessoas/famílias.

Também na análise da distribuição funcional da renda, foi estimada a contribuição do SM na elevação da parcela da remuneração do trabalho no PIB, verificando-se igualmente seu papel favorável. Pouco mais de $60 \%$ do aumento da participação dos rendimentos no PIB no período analisado poderiam estar associados aos efeitos do SM sobre o rendimento médio da população ocupada assalariada.

Tendo em vista a manutenção da atual legislação do SM até 2019, seria de se esperar a permanência do efeito redistributivo do SM nos próximos anos. Ocorre, entretanto, que desde 2014 a economia parou de crescer e que em 2015 e 2016 houve 
forte queda do PIB. Como o crescimento real do SM é baseado no aumento do PIB de dois anos anteriores, dificilmente haverá crescimento real para o SM até 2019.

Tais resultados mostram que, apesar do sucesso da política de aumento do SM em termos distributivos nos últimos anos, outras alternativas deverão ser encontradas para a continuidade da evolução favorável do SM e da melhoria da distribuição de renda no futuro.

Em primeiro lugar, é indispensável que a atual crise política e econômica seja superada e que a economia volte a crescer. Por outro lado, é preciso enfrentar o baixo ritmo dos investimentos dos últimos anos, necessários para a retomada do crescimento econômico. Em terceiro lugar, como consequência da própria recuperação da economia e dos investimentos, é necessário aumentar os atuais níveis de produtividade da economia brasileira, reconhecidamente baixos, mesmo em comparação com países menos desenvolvidos. Tal combinação de resultados poderia criar condições para a retomada do crescimento do SM no futuro quando a atual legislação tiver se encerrado.

\section{Bibliografia}

AFONSO, L. E.; PEREDA, P. C.; GIAMBIAGI, F.; FRANCO, S. O salário mínimo como instrumento de combate à pobreza extrema: estariam esgotados seus efeitos? Economia Aplicada, v. 15. n. 4, 2011.

BALTAR, P.; DEDECCA, C.; KREIN, J. (Org.). Salário mínimo e Desenvolvimento. Campinas: Unicamp, 2005.

BARROS, R. P. A efetividade do salário mínimo em comparação com o Bolsa Família como instrumento de redução da pobreza e da desigualdade. In: BARROS, R.; FOGUEL, M.; ULYSSEA, G. (Org.). Desigualdade de renda no Brasil: uma análise da queda recente. Brasília: Ipea, 2007. v. 2.

BRITO, A. S. O papel do salário mínimo na redução da desigualdade na distribuição de renda no Brasil entre 1995 e 2013. Tese (Doutorado)-Programa de Pós Graduação em Economia, Universidade Federal Fluminense, Niterói, ago. 2015.

CORSEUIL, C.; SERVO, L. Salário mínimo e bem-estar social no Brasil. Uma resenha da literatura. Rio de Janeiro: Ipea, 2002. (Texto para Discussão, n. 880).

FAJNZYLBER, P. Minimum wage effects through the wage distribution: evidence from Brazil's formal and informal sectors. Cedeplar, Universidade Federal de Minas Gerais, 2001. (Texto para Discussão, n. 151).

FERREIRA, F.; LEITE, P.; MESSINA, J. A more level playing field? Explaining the decline in earnings inequality in Brazil, 1995-2012. International Research Initiative on Brazil and Africa (Iriba), Sept. 2014. (Working Paper, n. 12). 
FIRPO, S.; REIS, M. C. O salário mínimo e a queda recente da desigualdade no Brasil. In: BARROS, R.; FOGUEL, M.; ULYSSEA, G. (Org.). Desigualdade de renda no Brasil: uma análise da queda recente. Brasília: Ipea, 2007. v. 2.

FOGUEL, M.; RAMOS, L.; CARNEIRO, F. The impact of minimum wage on the labor market, poverty and fiscal budget in Brazil. Rio de Janeiro: Ipea, 2001. (Texto para Discussão, n. 839).

GIAMBIAGI, F.; FRANCO, S. Esgotamento do papel do salário mínimo como mecanismo de combate à pobreza extrema. Rio de Janeiro: Ipea, 2007. (Texto para Discussão, n. 1290).

HALLAK NETO, J. A distribuição funcional da renda e a economia não observada no âmbito do sistema de contas nacionais do Brasil. Tese (Doutorado)-UFRJ, Rio de Janeiro, 2013.

HALLAK NETO, J.; SABOIA, J. A distribuição funcional da renda no Brasil: análise dos resultados recentes e estimação da conta da renda nos anos de informações preliminares do Sistema de Contas Nacionais. Revista de Economia Aplicada, Ribeirão Preto, FEA/USP, v. 18, n. 3, p. 483-513, jul./set. 2014.

IBGE. Sistema de Contas Nacionais - Brasil - referência 2010. Emprego e Remunerações Rio de Janeiro: IBGE, 2014. (Nota Metodológica, n. 14). Disponível em: ftp://ftp.ibge.gov.br/Contas_Nacionais/Sistema_de_Contas_Nacionais/Notas Metodologicas_2010/14_emprego_e_remuneracoes.pdf.

IBGE. Sistema de Contas Nacionais - Brasil 2010-2013. Rio de Janeiro: IBGE, 2015. Disponível em: http://biblioteca.ibge.gov.br/index.php/bibliotecacatalogo?view=detalhes\&id=294942.

KOMATSU, B. K. Salário mínimo, desigualdade e informalidade. Dissertação (Mestrado)-Universidade de São Paulo, São Paulo, 2013.

LAVINAS, L. Salário mínimo, linha de pobreza e benefícios assistenciais: desvincular é preciso? In: BALTAR, P.; DEDECCA, C.; KREIN, J. Salário mínimo e desenvolvimento. Campinas: Unicamp, 2005.

LEMOS, S. Minimum wage effects on wages, employment and prices: implications for poverty alleviation in Brazil. University of Leicester, 2005. (Working Paper, n. $05 / 15)$.

MENEZES FILHO, N.; RODRIGUES, E. A. S. Salário mínimo e desigualdade no Brasil entre 1981-1999: uma abordagem semiparamétrica. Revista Brasileira de Economia, Rio de Janeiro, v. 63, n. 3, jul./set. 2009.

NEDER, H. D.; RIBEIRO, R. Os efeitos distributivos do salário mínimo no mercado de trabalho brasileiro no período 2002-2008: enfoque a partir de distribuições contrafactuais. Pesquisa e Planejamento Econômico, v. 40, n. 3, dez. 2010.

NERI, M.; GONZAGA, G.; CAMARGO, J. Salário mínimo, efeito farol e pobreza. Revista de Economia Política, v. 21, n. 2, 2001. 
NERI, M.; GIAMBIAGI, F. Previdência social e salário mínimo: o que se pode fazer respeitando a restrição orçamentária? Revista do BNDES, v. 7, n. 13, 2000.

OLIVEIRA, R. B.; HOFFMANN, R. Evolução do emprego e dos salários na agricultura brasileira, 1995 a 2013. In: CONGRESSO DA SOCIEDADE BRASILEIRA DE ECONOMIA, ADMINISTRAÇÃO E SOCIOLOGIA RURAL (SOBER), 53, João Pessoa, 2015.

SABOIA, J. O salário mínimo e seu potencial para a melhoria da distribuição de renda no Brasil. In: BARROS, R.; FOGUEL, M.; ULYSSEA, G. (Org.). Desigualdade de renda no Brasil: uma análise da queda recente. Brasília: Ipea, 2007. v. 2.

SABOIA, J. Efeitos do salário mínimo sobre a distribuição de renda no brasil no período 1995/2005 - resultados de simulações. Econômica, v. 9, n. 2, 2007.

SABOIA, J. Elasticidades dos rendimentos do trabalho em relação ao salário mínimo: a experiência de um período recente de crescimento do salário mínimo. Economia e Sociedade, Campinas, v.19, n. 2, 2010.

SABOIA, J. Salário mínimo e distribuição de renda no brasil - potencial e limites. In: BARBOSA, N.; PESSOA, S.; MOURA, R. L. (Org.). Política de salário mínimo para 2015-2018: avaliações de impacto econômico e social. Rio de Janeiro: Elsevier, 2015.

SABOIA, J.; KUBRUSLY, L. S. Indicadores para o mercado de trabalho metropolitano no Brasil. Rio de Janeiro: Instituto de Economia / UFRJ, 2014. (Texto para Discussão, n. 21)

SOARES, S. O impacto distributivo do salário mínimo: a distribuição individual dos rendimentos do trabalho. Rio de Janeiro: Ipea, 2002. (Texto para Discussão, n. 873).

SOARES, S. Análise do bem-estar e decomposição por fatores da queda na desigualdade entre 1995 e 2004. Econômica, v. 8, n. 1, 2006.

SOARES, S. A distribuição dos rendimentos do trabalho e a queda da desigualdade de 1995 a 2009. Boletim Mercado de Trabalho - Conjuntura e Análise, ano 15, n. 45,2010 .

SOUZA, P. R.; BALTAR, P. E. Salário mínimo e taxa de salários no Brasil. Pesquisa e Planejamento Econômico, v. 9, n. 3, p. 629-660, 1979.

ULYSSEA, G.; FOGUEL, M. Efeitos do salário mínimo sobre o mercado de trabalho brasileiro. Rio de Janeiro: Ipea, 2006. (Texto para Discussão, n. 1168).

UNITED NATIONS (UN). System of National Accounts 2008 [SNA-2008]. New York: United Nations, 2009. Disponível em: http://unstats.un.org/unsd/nationalaccount/docs/SNA2008.pdf. 